The necessary cooling may be estimated in the following way: Supposing the solution to be a mixture, and to be cooled below its normal freezing-point, then, on solidification, the temperature would rise to this point, but if this solidification involved a chemical decomposition which absorbed $x$ cal., the rise of temperature would be thereby reduced, the reduction thus caused amounting to $x \div$ the heat capacity of the solution. As the heat absorbed in the decomposition of the various hydrates of sulphuric acid is known, we can calculate the lowering produced by their presence.

TABLE II.-Freezing-Points of Solutions of Sulphuric Acid.

\begin{tabular}{|c|c|c|c|c|c|c|c|}
\hline \multirow{2}{*}{$\begin{array}{c}\text { I. } \\
\text { Per cent. } \\
\mathrm{H}_{2} \mathrm{SO}_{4} .\end{array}$} & \multicolumn{4}{|c|}{ Calculated. } & \multirow{2}{*}{$\begin{array}{l}\text { IV. } \\
\text { Found } \\
\text { F.p. }\end{array}$} & \multicolumn{2}{|c|}{ Next hydrate. } \\
\hline & $\begin{array}{c}\text { II. } \\
\text { Mech. }\end{array}$ & $\begin{array}{l}\text { III. } \\
\text { Phys. }\end{array}$ & $\begin{array}{c}\text { IV. } \\
\text { Chem. }\end{array}$ & $\begin{array}{c}\text { V. } \\
\text { Total. }\end{array}$ & & $\begin{array}{l}\text { VII. } \\
\text { Calc. }\end{array}$ & $\begin{array}{l}\text { VIII. } \\
\text { Found }\end{array}$ \\
\hline $\begin{array}{r}0.068 \\
0.362 \\
1.06 \\
4^{\circ} .02 \\
8.59 \\
18.49 \\
29^{\circ} .53\end{array}$ & $\begin{array}{l}0.0209 \\
0.1114 \\
0.3275 \\
1^{2} 285 \\
2.879 \\
6.96 \\
6^{2} 86 \\
1285\end{array}$ & $\begin{array}{l}0^{\circ} 0 \\
0.0004 \\
0.0044 \\
0.071 \\
0.071 \\
0.388 \\
3.23 \\
\times 8.82\end{array}$ & $\begin{array}{l}\text { 0.0110 } \\
0.0248 \\
0.0589 \\
0.077 \\
0.189 \\
0^{\circ} .59 \\
3^{\circ} 50\end{array}$ & 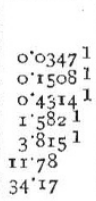 & $\begin{array}{l}0^{\circ} 0354 \\
0^{\circ} 1582 \\
0.4272 \\
\mathrm{I}^{\circ} .59 \\
3.80 \\
\mathrm{Ir} \cdot 83 \\
34.00\end{array}$ & $\begin{array}{r}\text { Per } \\
\text { cent. } \\
0.37 \\
1.43 \\
3.54 \\
3.54 \\
84^{\circ} .0 \\
18^{\circ} 7 \\
29^{\circ} 7 \\
375\end{array}$ & \begin{tabular}{|} 
Per \\
cent. \\
0.36 \\
$0^{\circ} .05$ \\
$4 \% 2$ \\
$4^{\circ} .59$ \\
18.49 \\
$28^{\circ} .5$ \\
$37^{\circ} 7$
\end{tabular} \\
\hline
\end{tabular}

In Cols. II., III., and IV., I have given the depression due to the three above-mentioned causes in the case of certain solutions, Col. V. containing their sum; and it will be seen what a small proportion of this. total lowering can be attributed to purely chemical causes. With most solutions it does not exceed ro per cent. of the total, and with weak solutions, such as are generally used in freezing-point determinations-say 5 per cent. -it amounts to considerably less than $0^{\circ} \cdot \mathbf{I}$; this, too, in the case of sulphuric acid, where the heat of formation of the higher hydrates is greater than with any other known substance.

The reason, therefore, why the deviations from constancy are so small as to have escaped detection hitherto, and the reason why solutions behave almost as if their chemical nature was non-existent, becomes apparent; but this near approach to constancy and regularity, instead of proving the correctness of the physical theory and giving a death-blow to the chemical theory, is really one of the strongest arguments which can be adduced in favour of the latter. If the hydrate theory is right, the influence of hydrates must often be nearly inappreciable.

But it is not only a general concordance between the found and calculated magnitude of the irregularities which the hydrate theory is capable of affording, but a concordance so exact that the precise value of the deviation at any point may be calculated. In Col. VI. of Table II. are given the observed freezing-points of the solutions, and these show an average difference of but $0^{\circ} .004$ for the three weaker solutions, and $0^{\circ} .06$ for the four stronger solutions, from those calculated (Col. V.). The Iast two columns exhibit this concordance in a different manner; from the observed freezing-point we can calculate the composition of the hydrates which must exist in the solution (Col. VII.), and these are found to agree so fully with those indicated by the examination of the curved figures representing various properties of the solution (Col. VIII.) that the maximum difference between the two is only 0.48 in the percentage of acid present.

When we can by simple calculations, based on one series of determinations, prove that the hydrates in solution must be the same as those which totally independent experiments have led us to suppose, we have, I think, arrived at proof as nearly absolute as it is possible to conceive; and, if I have succeeded in showing that this proof may be accepted without in any way rejecting the facts on which the advocates of the osmotic pressure theory rely-approximate constancy, approximate regularity, and approximate similarity between dissolved and gasecus matter-I shall feel that I have done far better work than the mere establishment of the hydrate theory, by pointing out a possible modus vivendi for both theories almost in their entirety, and by helping to break down that wall of separation between physicists and chemists which is fast crumbling into dust.

$$
\text { Spencer Umfreville Pickering. }
$$

I The actual total has been increased by 10 4 per cent. of its value to give the figures quoted in these five cases, for reasons which will be given elsetions, as they have been quoted in the absence of the original calculations.

\section{A TEACHING UNIVERSITY FOR LONDON.}

$\mathrm{T}^{\mathrm{H}}$ HE following letter has been addressed to the Lord President of the Privy Council :-

My LORD, - We, the undersigned, the President of University College, London, and the Principal of King's College, London, beg leave to address your Lordship in reference to the joint petition from the Councils of our two Colleges for the incorporation of a Teaching University in London, which has for some time been before the Privy Council. Your Lordship had the goodness to receive a deputation from the Councils of our two Colleges in July 1889 ; and your Lordship then intimated your judgment that the University of London should be allowed a reasonable time in which to propose a new charter in accordance with the recommendations of the Royal Commission on the question of a Teaching University in London. In obedience to this intimation from your Lordship, our Councils have, at the request of the Senate, entered into negotiation with them, and have consented, subject to the satisfactory settlement of some points affecting the Faculties of Law and Medicine, to a scheme for our union with the University, embodying a separate system of graduation for our students in the Faculties of Arts and Science. We desire that power should be reserved in certain events to make similar arrangements in regard to the Faculty of Law. With respect to medicine, the Senate have stipulated that they should be at liberty to make different arrangements, separately from our Colleges; and in the absence of opportunities for conference with the other institutions specially interested in this Faculty, we have not thought fit on this ground to break off the negotiations; but we reserve power to reconsider our position, if arrangements are contemplated by which it would be seriously affected. We claim, further, as essential to the efficiency of our teaching in science, that our medical students, for the purpose of their examination in pure science, known as the "Preliminary Scientific Examination," shall be considered as belonging to the Faculty of Science on the teaching side of the University, and not to a separate Faculty of Medicine.

Having been informed that urgent protests are raised by University Colleges in the country, particularly at Birmingham, against influence being given to London Colleges in the Senate while they are excluded, we beg to remind your Lordship that the amalgamation of the proposed Teaching University for London with the existing University was not our proposal, but has been, thus far, accepted by us in deference to the principal Report of the Royal Commissioners. We consider that, if this amalgamation is effected, we are entitled to a representation on the governing body of the reconstituted University proportionate to our concern in University teaching for London, considered as one of its two spheres of work ; and that the nature of the case does not admit of a similar effective representation of institutions elsewhere. If this reconstitution of the existing Uniwersity should be found, by reason of such opposition, or for any other reason, impracticable, we desire to be replaced in our original position, as petitioners for the establishment in London of a Teaching University upon the lines of our petition presented in I 887 , and of the draft charter thereto appended, to which, in that case, we still respectfully adhere.

We have the honour to remain, your Lordship's obedient humble servants,

\section{JOHN ERIC ERICHSEN, President of University College, London. Henry Wace, Principal of King's College, London.}

\section{UNIVERSITY AND EDUCATIONAL INTELLIGENCE.}

CAMBridge. - The election of a Professor of Mechanism and Applied Mechanics, in succession to Prof. James Stuart, will take place on November I2. The names and testimonials of candidates are to be sent to the Vice-Chancellor by Saturday, November 8. The electors are the Vice-Chancellor, Mr. W. Airy, Dr. Besant, Sir F. J. Bramwell, Dr. Cayley, Mr. H. Darwin, Mr. Martin, Dr. Phear, and Lord Rayleigh. The stipend is $£ 700$. The Senate has approved a new scheme for the management of the department, under which the Professor is directly responsible for the carrying on of the workshops.

Mr. Chaplin, the President of the Board of Trade, has proposed to the Chancellor that the University should undertake 
the systematic education of students of agriculture. The question of funds stands in the way, but a syndicate is to be appointed to consider the question, and it is hoped that by a subvention from the County Councils, or by private benefaction, means may be found for the formation of an agricultural department.

Mr. Wynter Blyth and Dr. Ransome have been appointed additional examiners in Sanitary Science. Between fifty and sixty candidates presented themselves for examination, of whom about forty satisfied the examiners, and have received the University diploma in Public Health.

Mr. J. G. Adami, of Christ's College, has been elected to the John Lucas Walker Studentship in Pathology, in succession to Dr. William Hunter, of St. John's College.

Mr. E. Lloyd Jones has been appointed Demonstrator of Pathology in succession to Mr. Adami, resigned.

Mr. L. R. Wilberforce, of Trinity College, has been appointed Demonstrator of Physics, in succession to Mr. F. Newall, resigned.

The honorary degree of M.A. has been conferred on Dr. Joseph Griffiths, Assistant to the Professor of Surgery, and Pathologist to Addenbrooke's Hospital.

Dr. Donald MacAlister, of St. John's College, has been appointed Assessor to the Regius Professor of Physic.

The following have been nominated as Examiners in Natural Science :-Physics: Prof. Carey Foster, F.R.S., and R. T. Glazebrook, F.R.S. Elementary Physics : Prof. J. J. Thomson, F.R.S., and L. R. Wilberforce. Chemistry: Prof. Liveing, F.R.S., and Prof. Emerson Reynolds, F.R.S. Elementary Chemistry: M. M. Pattison Muir and Dr. Ruhemann. Geology: Prof. A. H. Green, F.R.S., and J. E. Marr. Botany : Prof. D. H. Scott and Prof. J. R. Green. Zoology: Prof. Ray Lankester, F.R.S., and A. E. Shipley. Elementary Biology: Prof. Marshall Ward, F.R.S., and A. Sedgwick, F.R.S. Anatomy: Prof. Macalister, F.R.S., and Prof. Windle. Physiology: L. E. Shore and C. S. Sherrington. Pharmaceutical Chemistry: H. Robinson and E. H. Acton.

\section{SOCIETIES AND ACADEMIES.}

PARIS.

Academy of Sciences, October I3.-M. Hermite in the chair.-M. Tisserand presented the second volume of his "Traité de Mécanique Céleste," and noted that it deals principally with two subjects-viz. the figure of celestial bodies, and their movement of rotation.-Presentation of the fifth volume of the "Bulletin du Comité international de la Carte du Ciel "; state of progress of preliminary works, by Admiral Mouchez.On a photograph of the Ring Nebula in Lyra, obtained at Algiers Observatory, by the same author.-On a photograph obtained with a nine hours' exposure at Toulouse Observatory, by M. B. Baillaud. (For the three above communications, see Our Astronomical Column.)-Observation of D'Arrest's comet (rediscovered by Mr. Barnard on October 6, 189o) made at Paris Observatory with the West Tower equatorial, by M. G. Bigourdan. The observation for position was made on October ro. On the linear equations from partial derivatives, by M. A. Petot. -Vibrations of a platinum wire rendered incandescent by an electric current, under the influence of successive interruptions of this current, by M. T. Argyropoulos. The author has stretched horizontally a platinum wire, $0 \% 70$ metre long and less than a millimetre in diameter, and has raised it almost to white heat by means of an electric current. By inserting a commutator in the circuit, the wire immediately vibrated, and became subdivided into a series of waves having well-marked ventral segments and nodes. The number of segments was augmented by very slowly decreasing the tension of the wire. On increasing the tension the number was diminished until the incandescent wire vibrated transversely with a single ventral segment at the middle. - Combinations of cyanide of mercury with lithium salts, by M. Raoul Varet. The following compounds have been prepared : (r) an iodocyanide of mercury and lithium, having the composition $\mathrm{HgCy}_{2}, 2 \mathrm{LiCy}, \mathrm{HgI}_{2}, 7 \mathrm{H}_{2} \mathrm{O}$; (2) a bromocyanide of the same metals, for which the formula $2 \mathrm{HgCy}_{2}, 2 \mathrm{LiBr}, 7 \mathrm{H}_{2} \mathrm{O}$ is given ; (3) a chlorocyanide of mercury and lithium, of doubtful composition.-Researches as to the best conditions for the preparation of mono-isobutylamine in quantity, by M. H. Malbot.- - On a general process for the synthesis of $\beta$-ketonic ethers and nitriles, by M. L. Bouveault. The author gives the most general method for the formation of $\beta$-ketonic nitriles, and shows that these bodies may readily be transformed into the corresponding ethers. The method is given in sufficient detail, and several examples of its application shown.-Upon the presence and the disposition of trehalose in mushrooms, by M. Em. Bourquelot.-On the lateral nerve of Cyclopteridæ, by M. Frédéric Guitel.-Physiological researches on floral envelopes, by M. Georges Curtel. It is concluded that (I) the flower possesses energetic respiratory and trarts piratory functions, superior in general to those of the leaf.of the same plant; (2) the assimilation is generally feeble, and cloaked or much diminished by the very intense respiration; $(3)$ the volumetric proportion of carbon dioxide emitted to oxygen absorbed is always small, and less than unity.-On the porphyritic eruptions of Jersey, by M. A. de Lapparent.

\section{Sydney.}

Royal Society of New South Wales, August 6.-Dr. Leibius, President, in the chair.-Seven new members were elected.-A letter was read from the Committee appointed by the Victorian branch of the Royal Geographical Society of Australasia and the Royal Society of Victoria conjointly, inviting the co-operation of the Royal Society of New South Wales in carrying out the proposed Swedish-Australian expedition to the Antarctic Regions, and stating that Barons Nordenskiöld and Oscar Dickson had promised to defray half the cost of the expedition, providing an equal amount $(£ 5000)$ was raised in the colonies. - The following papers were read :-On the theory of repetition measures of angles with theodolites, by G. $H$. Knibbs. - Record of hitherto undescribed plants from Arnheim's Land (part ii.), by Baron Ferd. von Mueller, K.C.M.G., F.R.S. - On the Australian aborigines, varieties of food and methods of obtaining it, by W. T. Wyndham.-On some photographs of the Milky Way, recently taken at the Sydney Observatory, by H. C. Russell, F.R.S.

September 3.-Dr. Leibius, President, in the chair.-The fol. lowing papers were read :-Record of hitherto undescribed plants from Arnheim's Land (part iii.), by Baron Ferd. von Mueller. - On the application of the results of testing Australian timbers to the design and construction of timber structures, by Prof. Warren.-Exhibits : Enlargement of photograph of a negative of Fresnel's interference bands, for lecture purposes, by Prof. Threlfall ; Edison's latest perfected phonograph, by C. L. Garland.

\section{CONTENTS.}

British Farm, Forest, Orchard, and Garden Pests . 609

Tornadoes. By H. F. B. ......... 612 Our Book Shelf :-

Beuttler: "Inorganic Chemistry: the Chemistry of

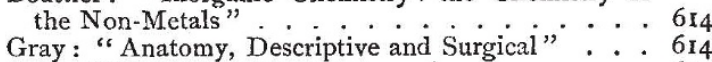

Ball: "The Story of the Heavens"..... . 614

Letters to the Editor:-

The Passage of Electricity through Gases.-Prof.

J. J. Thomson, F.R.S. . . . . . . 6 6

Changing the Apparent Direction of Rotation.Hercules Macdonnell . . . . . . . . . 6I4

Earthquake Tremors.-H. G. Dixon . . . . . 6 6I5

A Ball of Fire.-Charles Randolph : . . . . . 615 Hydrazoic Acid-a New Gas. By A. E. Tutton . . 615

Prof. S. A. Hill. By H. F. B. . . . . . . . . 6I6

John Hancock ......... . . 6r 6

Notes ............. 6I7

Our Astronomical Column:-

Objects for the Spectroscope.-A. Fowler . . . . 619

Photographs of Nebulæ . . . . . . . . . 6rig

Stars having Peculiar Spectra . . . . . . . . . 6r9

The Photographic Chart of the Heavens . . . . . 619

D'Arrest's Comet . . . . . . . . . . . . . . . . 619

A New Asteroid . . . . . . . . . . . . . . . 619

The Teaching of Botany . . . . 620

The Present Position of the Hydrate Theory of

Solution. (With Diagrams.) By Prof. Spencer

Umfreville Pickering, F.R.S. . . . . . . 626

A Teaching University for London. . . . . . .63I

University and Educational Intelligence . . . . . 63I

Societies and Academies ......... 632

NO. IO95, VOL. 42 